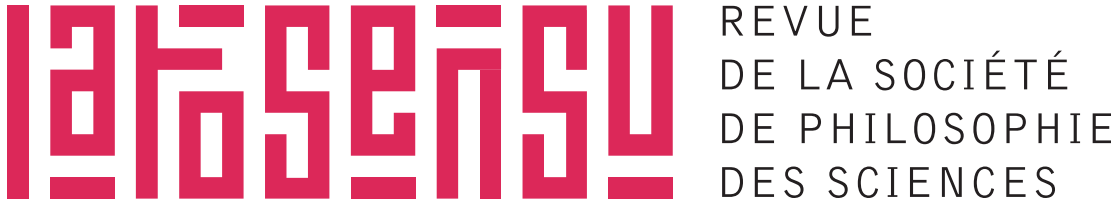

$\operatorname{Vol} 4 N^{\circ} 22017$

DOI http://dx.doi.org/10.20416/lsrsps.v4i2.793

Maël Lemoine

NEITHER FROM

WORDS, NOR FROM

VISIONS:

UNDERSTANDING

P-MEDICINE FROM

INNOVATIVE TREAT-

MENTS.

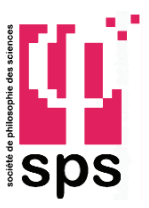

SOCIÉTÉ DE PHILOSOPHIE DES SCIENCES (SPS) 


\section{TIVE TREATMENTS.}

\author{
Sommaire \\ 2 - The boy who lived: tech- \\ nologies and interpretations \\ defining $p$-medicine \\ 3 - Molecularization and \\ computerization are the two \\ pillars of $p$-medicine \\ 4 - Monoclonal antibodies are \\ the spearhead of $p$-medicine \\ 5 - Mabs as archetypes for $p$ \\ -medicine \\ 6 - Conclusion: The name and \\ the thing
}

\begin{abstract}
Despite its vagueness, 'Personalized', 'Precision', 'P4', 'P5', 'individualized', 'stratified medicine - or p-medicine in short-has become an increasingly popular term in biomedical literature. Philosophers have attempted to analyze what these various terms involve and have discussed consequences for medical practices. In this article, I address a different, but crucial question: what has made this project of p-medicine convincing to so many? My argument is that without real achievements, it would not have been the case. I also make the case that these achievements stem from the domain of monoclonal antibodies (mab), a new type of drug that prompted talks of personalized, precise, stratified, etc., medicine. In conclusion, while it may be possible to label any projection in the future of medicine as ' $p$-medicine', it is impossible to overlook mab-medicine as the spearhead of current research programs in $\mathrm{p}$-medicine and medical practices that follow.
\end{abstract}

Key-words: personalized medicine, precision medicine

\section{1 - Introduction}

Many have claimed that a revolution has occurred in medicine since the post-genomics era arose around 2000. Several names have been used to refer to this revolution: 'Personalized medicine' (Langreth and Waldholz 1999), 'precision medicine' (National Research Council [US] Committee on A Framework for Developing a New Taxonomy of Disease 2011), 'stratified medicine' (Food and Drug Administration 2014), 'P4 medicine'(Hood and Friend 2011), and, less notably, 'individualized medicine' (Fischer and al. 2015) and ' $\mathrm{P} 5$ medicine' (Pravettoni and Gorini 2011; Khoury and al. 2012). Apart from 'personalized', which was the first to appear, adjectives are sometimes proposed to justify a definition that contrasts what this medicine 'truly' is with what a previously proposed term (most often 'personalized') would 'wrongly' suggest it is. Sometimes, the goal is to differentiate one innovative medicine from another. Moreover, each attempts to emphasize a different property of this (or these) new medicine(s). Table 1 provides some examples of the terminological confusion in the scientific literature. It differs from the best descriptive analysis of the occurrences of these names that I could find (Pokorska-Bocci et al. 2014).

Philosophers have tried to order this obvious conceptual mess (see Schleidgen et al. 2013 for an example). Indeed, it is tempting for a philosopher to analyze the difference between these names and their definitions so as to produce a conceptual map of meanings of some sort (Pokorska-Bocci et al. 2014). However, there are important limits to such an analysis.

First, sticking to the discussion of terms and their definitions is likely to either miss important aspects of the underlying realities or to mix the actual with the potential. For instance, in the review by Pokorska-Bocci et al. previously referred to, the exclusion criterion was precisely that no paper mentioning "specific therapy for specific condition" should be retained, but only papers discussing "general concepts" (Pokorska-Bocci et al. 2014).

Second, it is safe to assume that these terms mostly refer to the same enterprise in all its ramifications, and are thereby in competition, each of them having some rightful claim to be the most appropriate. Deciding is taking a side, if implicitly, which raises the question of a philosopher's (or sociologist's or historian's) motives. For instance, philosophers Green and Vogt describe in silico modeling as a recent medical development that fits well into personalized medicine under the form of $\mathrm{P}_{4}$ medicine; but one may reasonably ask why not precision or stratified medicine instead (Green and Vogt 2016)? The same sort of problem appears in many other contributions (Schleidgen et al. 2013; Boenink 2010; Fleck 2010; Bragazzi 2013), but few focus on the question of terms (see for instance Juengst et al. 2016) or approach it as a question to be negotiated among stakeholders (De Grandis and Halgunset 2016). For this reason, I will refer to all these terms collectively as 'p-medicine', so as not to decide whether it should be called 'personalized', 'precision', 'predictive', 'participatory', 'individualized', 'stratified', or anything else.

Third, each of these names refers to aspects of specific technologies or procedures, which it is also more or less arbitrary to emphasize for conceptual reasons. Arguments to decide which is the proper name or which is the central technology, 


\section{NEITHER FROM WORDS, NOR FROM VISIONS: UN- DERSTANDING P-MEDICINE FROM INNOVATIVE TREAT- MENTS.}

however, are necessarily weak since p-medicine often refers to potential rather than to actual procedures, so much so that there is an important futurological aspect to the choice of the name (Hedgecoe 2005; Tutton 2012). Evidence can be found in the proportion of editorials that refer to 'p-medicine' as compared to original research papers (see figure 1). Furthermore, scientific-along with marketing, political and epistemological-motives complicate the choice of a label. Under such constraints, explaining the evolution of language (see figure 2 and 3) invokes serious sociological, historical and philosophical questions.

For these reasons, it is impossible to answer such questions as: 'what is properly speaking p-medicine?' and 'how should it be properly called?', based on verbal or programmatic definitions. P-medicine is whatever one likes it to be, granted that we are 1) talking about new, but heterogeneous medical procedures and technologies, and 2) mostly referring to their future achievements. De Grandis and Halgunset's have already made this point and they insisted that context of use, ethical concerns and politics should also be taken into consideration in a negotiation over the meaning of the word (De Grandis and Halgunset 2016). This paper follows a different path. I suggest that a systematic, critical review of the actual achievements and current technologies and procedures undergirding talks of $\mathrm{p}$-medicine can provide the adequate basis of a descriptive definition, rather than a normative one.

Such an enterprise has not really been undertaken yet. It is the only approach that may clarify why precisely these words have been chosen with some persuasive force. In this paper, the methodological assumption is that actual achievements of 'p-medicine' are what really matters in the justification of any label, because only they justify so much discussion about such a project. The contention breaks down into two claims:

1) p-medicine is, strictly speaking, nothing but an ens rationis created by the legitimate desire to discuss the future consequences of medical innovation - as such everybody can define it as they like, there is no true or false definition, and most of those proposed are relevant, more or less depending on what you find is and is not interesting, or bet will change medicine (a claim close to De Grandis and Halgunset 2016).

2) however, there also are real achievements underneath so much ado. They make p-medicine an enterprise to be taken seriously not only for what may be projected, but mostly for what has already been achieved. Most of these achievements fall under the development of monoclonal antibodies (mabs). A less conceptual, but more adequate, description of the effective and current part of p-medicine would therefore be mab-medicine.

These two claims are indeed distinct. Moreover, it is predicta- 
ble that most readers, as philosophers, may agree with [1], but will probably feel uncomfortable with [2], which sounds more surprising.

The following inquiry proceeds as follows. Section 2 lists five technologies that po-
600 Figure 1. Editorials/Articles refering to $p$-medicine (source:pubmed)

400

200

0

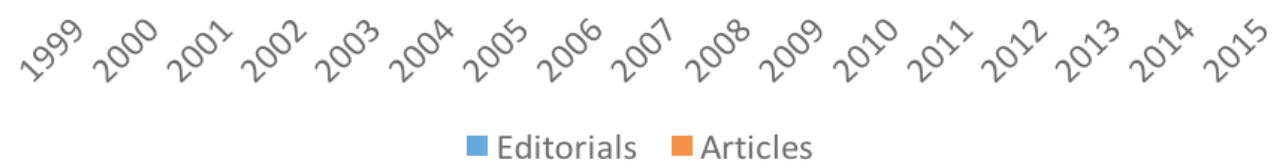

10000

Figure 2. Various terms to label the same thing through time (source: pubmed)

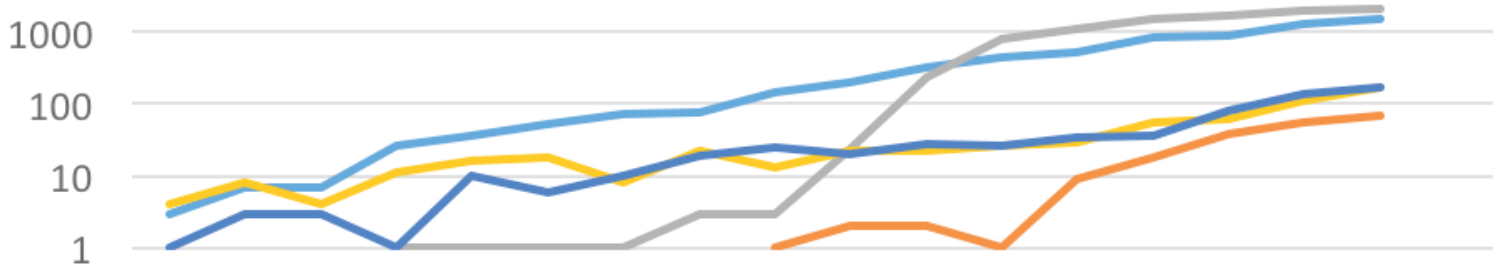

1

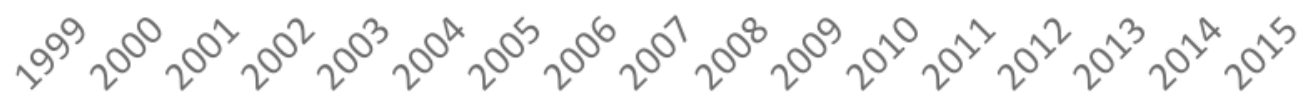

-Personalized - Stratified - Precision - Predictive - Individualized

tentially define p-medicine, namely: the massive use of biomarkers, systems biology, innovative treatments, big data processing, and a new paradigm of care. Section 3 sets molecularization and computerization of diseases as the two

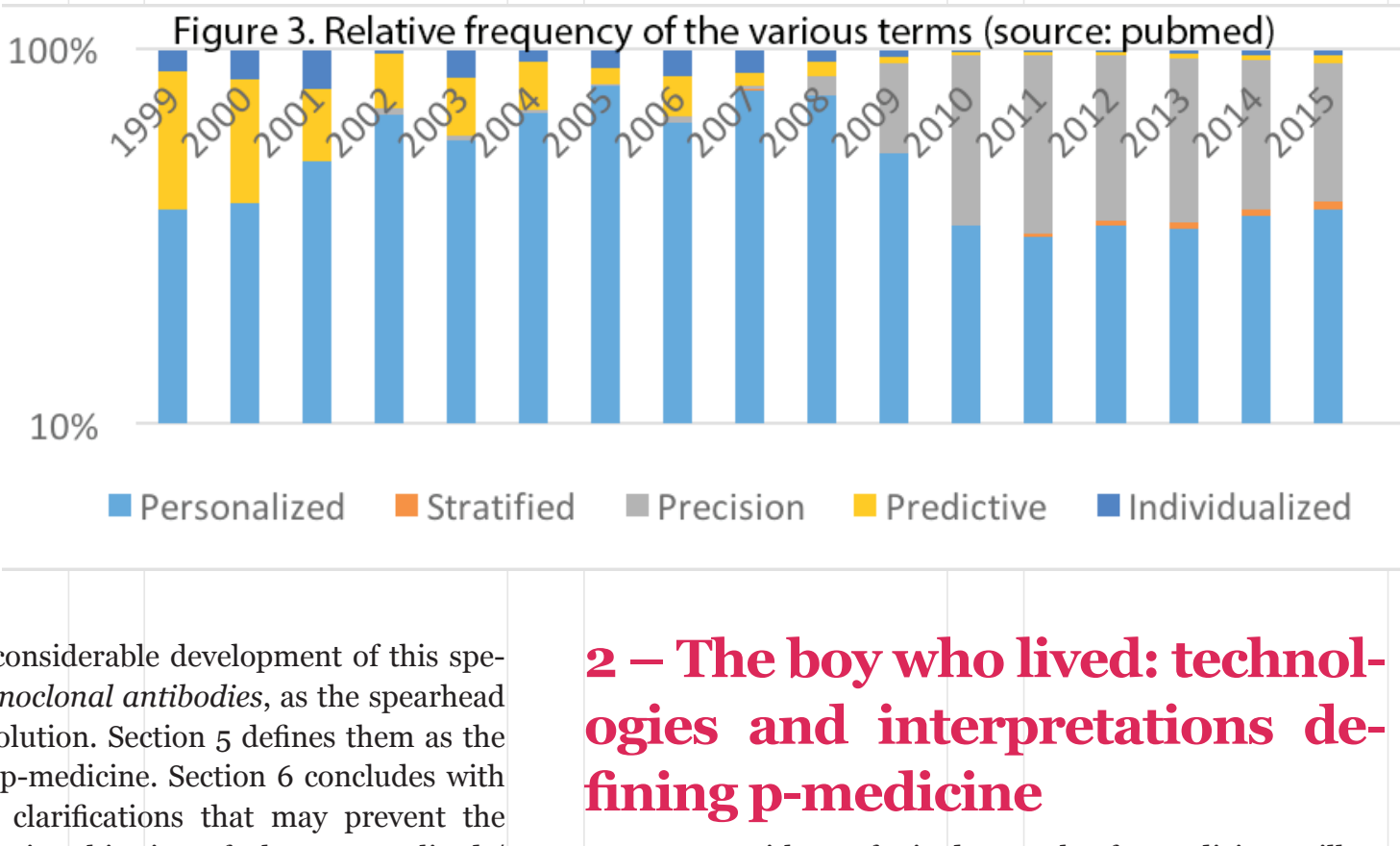

Let us start with an oft-cited example of p-medicine to illustrate what p-medicine consists in. It is considered the first successful application of whole-exome sequencing. The seminal paper detailing this case, which has about 500 citations on Google Scholar, was published in Genetics in Medicine in 2011 and describes an undiagnosed 15 month old child with symptoms similar to those of severe Crohn disease. An ex- 


\section{NEITHER FROM WORDS, NOR FROM VISIONS: UN- DERSTANDING P-MEDICINE FROM INNOVATIVE TREAT- MENTS.}

ome sequencing led to the identification of 16,124 genetic variants, within which further analysis selected a mutation in the $\mathrm{X}$-linked inhibitor of apoptosis (XIAP) gene, that is, a unique case of a previously unobserved Mendelian disease. The boy was successfully treated by an allogeneic hematopoietic progenitor cell transplant (Worthey et al. 2011). Note that other similar cases of individually tailored treatments have been both widely cited in professional literature and published in the general press (see for instance Mnookin 2014). ${ }^{1}$

Before examining the various interpretations that have been proposed, let us make two important caveats. First, this example is not typical of the revolution of $\mathrm{p}$-medicine for three reasons: cases of individually-tailored therapies in p-medicine are much rarer than in other technologies; resorting to cell transplantation is equally rare; and, this form of Inflammatory Bowel Disease is unique. Yet it is paradigmatic in so far as it involves 'precision', is molecular, genomic, personalized, computerized, and preventative: the very terms found in typical definitions of what p-medicine consists in. Second, it is not exactly true that whatever made this treatment possible is a decisively new technology. Treating one boy, treating him in a very precise manner, treating him preventively, etc., has not become possible all of a sudden. On the contrary, all this has been possible for years, even decades. More generally, medicine, it has often been noted, has not suddenly become personal, precise, predictive, stratified, etc., but has been so for a long time. Rather, with p-medicine, medicine is (or is becoming) more personal, more stratified, more precise, more predictive, etc. Furthermore, this progress is not just a gradual improvement, but thought of as a significant acceleration. $\mathrm{P}$-medicine is supposed to be a revolution because it has been making medicine a great deal more personal, precise, predictive, etc.

That said, I suggested an analysis focused on the technologies that make such cases possible. Five sets of technologies, I propose, have been said to have brought these fundamental changes to medicine. The papers referred to above mentioned them all, and only they were mentioned in all of them.

1) The use of biomarkers. A biomarker, or a biological marker, is a molecule significantly associated with health-related states, that can be detected and measured (Biomarkers Definitions Working Group. 2001; Strimbu and Tavel 2010). Examples are: blood levels of $X$, genetic polymorphisms, the exome of a tumor, etc. In the boy's case, the key biomarker is one SNP, that is a tag for a specific mutated gene called XIAP, which was never observed before in association with Crohn's disease. For the past two decades, biomarkers have been intensely investigated and increasingly used in clinical practice for diagnostic, therapeutic and prognostic purposes. In comparison to labels such as 'precision medicine', which hits a total record of 10,000 papers on pubmed, the entry 'biomarker' returns ca. 800,000 papers as of Sept. $1^{\text {st }}, 2016$. The trend looks to be more a constant accumulation rather than an acceleration. An already old list of biomarkers of interest can be found in Barh, Blum, and Madigan (2011, p. 348).

2) Theorizing in the framework of systems biology. Basic biomedical science is shifting from traditional box and arrow' models to more complex models required by the flood of data now available, mainly through -omics. In the boy's case, the performed exome sequencing resulted in 16,124 variants as compared to the human reference sequence. A selection had to be done according to various criteria. For instance, as the disorder was not known, the first hypothesis was that this mutation would also be unknown, which reduced the number of potential variants to 1,527 , of which only 879 would result in a different amino-acid. One of the most important selection criteria is Polyphen, "a tool that predicts the impact of an amino acid substitution on the structure and function of a human protein" (Worthey et al. 2011). This software reduced the number very significantly so that, in the end, by way of a priori reasoning, only one mutation is left. Polyphen, developed by Harvard University (Adzhubei et al. 2010), calculates the probability that a mutation is deleterious, based on methods typical of systems biology. More generally, many mathematical and methodological innovation are increasingly investigated and resorted to in research, as well as in practice. A key paper concerning the introduction of systems biology into medical science is Ideker, Galitski, and Hood's (2001) while Barabási, Gulbahce, and Loscalzo's (2011) concerns the introduction of 'network medicine'.

3) Using conceptually innovative treatments. Innovative treatments that have appeared within the last two decades clearly seem to utilize significantly different molecules. It is not so much the number of new molecules on the market, as it is the number of innovative treatments. In the boy's case, it is a cell transplant from the mother. Cell transplant is part of p-medicine's arsenal, but not the most resorted to. There is, for instance, a tendency to repurpose already existing drugs, yet, nonetheless, significantly new molecules have entered the market, either resulting from 'drug design' (as imatinib and other tyrosine kinase inhibitors [TKI]), or from advanced biological engineering (as trastuzumab and other monoclonal antibodies [mabs]).

4) Big Data: Computer-assisted research and treatment. New data of many kinds can now be collected, stored, categorized, or crunched into decisions. In the specific domain of oncology, Vice-President Joe Biden launched the Cancer Moonshot Initiative in 2011, a project creating a shared platform of biological data relevant to cancer. In the boy's case, big data computer technology made a full 


\section{NEITHER FROM WORDS, NOR FROM VISIONS: UN- DERSTANDING P-MEDICINE FROM INNOVATIVE TREAT- MENTS.}

exome sequencing, a comparison with highly conserved SNPs in non-diseased humans, and a comparison with all previously known mutations of the gene called XIAP. More generally, numerous platforms have been developed to collect traditional medical records, results of whole genome sequencing, metagenomic and transcriptomic data, in humans as well as in animal models, and even data from wearable devices (see Canuel et al. 2015 for a review of the main platforms).

5) A new paradigm of care. P-medicine seems to involve a shift in the practices of medical care. The acknowledgment section in the original paper reporting the boy's case testifies to the unusual number of people who cooperated in his care (Worthey et al. 2011). Doctor-patient relationships, decision processes, patient networking, but also health policies (including regulation of drug approval), have all undergone significant changes in relation to p-medicine.

Altough all these technologies were involved in this case, different interpretations of what is going on can be given. Each expectedly emphasizes different technologies and implements them into a different strategy. To comprehensively situate interpretations of p-medicine strategy, I researched each general paper concerning this boy's procedure that has been cited over 100 times. This allowed me to reconstitute three different narratives of what exactly is the p-medicine that saved this 'XIAP' boy's life. These narratives are often proposed at different places in the same paper or even meshed together.

1) An individual boy with a unique condition may be saved because powerful, accurate and trustworthy devices are available in the clinics.

This view is championed by an FDA report published in 2014. 'P-medicine' still is 'personalized medicine' to the FDA. As a regulator, i.e., not a researcher, a pharmaceutical company, a policy-maker, a patient, a health practitioner, etc., the FDA insists on the medical products that allow for the detection and processing of biomarkers on the one hand, and the treatment of the condition on the other hand:

"Personalized medicine generally involves the use of two medical products - typically, a diagnostic device and a therapeutic product - to improve patient outcomes. A diagnostic device is a type of medical device. Diagnostic devices include both in vitro tests such as assays used in measurement of genetic factors and in vivo tests, such as electroencephalography (EEG), electrocardiography (EKG), or diagnostic imaging equipment." (Food and Drug Administration 2014)

Only such products can support the grand ambition of

\begin{abstract}
"the tailoring of medical treatment to the individual characteristics, needs and preferences of a patient during all stages of care, including prevention, diagnosis, treatment and follow-up." (Food and Drug Administration 2014)
\end{abstract}

This general interpretation, which focuses on the idea that available devices work, appears is most frequently in the literature regarding this particular case. Being no longer reserved for researchers, many credit the broadened use of genomic platforms with saving the boy's life (see for example Chan and Ginsburg 2011; Soon, Hariharan, and Snyder 2013); others, however, insist on the availability of the shared infrastructure to compare data on a large scale (Manolio et al. 2013).

2) The ability to bypass traditional disease entities and use genomic database to target the relevant biomarker, identify the involved biological network and imagine a potentially efficient treatment: this is what saved this boy's life.

The National Research Council endorses the corresponding general view in a 2011 report. They played a role in the shift from 'personalized' to 'precision' in p-medicine:

\begin{abstract}
"as used in this report, "precision medicine" refers to the tailoring of medical treatment to the individual characteristics of each patient. It does not literally mean the creation of drugs or medical devices that are unique to a patient, but rather the ability to classify individuals into subpopulations that differ in their susceptibility to a particular disease, in the biology and/or prognosis of those diseases they may develop, or in their response to a specific treatment." (National Research Council (US) Committee on A Framework for Developing a New Taxonomy of Disease 2011)
\end{abstract}

P-medicine generally consists in linking biomarkers to treatments through innovative means, mainly, huge shared repositories where data is organized according to a new taxonomy, instead of observed clinical signs and traditional disease entities. This general view supports a second tendency in the interpretation of the XIAP boy's case: to emphasize the 'diagnosis' of a new - even potentially unique - condition, thanks to (mainly genomic) biomarkers (see examples in Fan, Han, and Liu 2014; McCarthy, McLeod, and Ginsburg 2013; Li and Meyre 2014).

3) The ability to generate many hypotheses and then reduce the number to the only one to fit the data for this individual, this is what saved this boy.

This view is for instance that of the advocates of ' $\mathrm{P} 4$ Medicine'. They consider that 1) -omics data is treated through 2) systems medicine models which provides 3) stratification, which makes possible 4) personalized care (which is also 5) participatory, 6) predictive and 7) preventive). The critical component is the computer power capable of reducing data 
REVUE

DE LA SOCIÉTÉ

DE PHILOSOPHIE

DES SCIENCES

\section{NEITHER FROM WORDS, NOR FROM VISIONS: UN- DERSTANDING P-MEDICINE FROM INNOVATIVE TREAT- MENTS.}

p-medicine possible, was molecularization through the study of the genome, and computerization for storing and manipulating such data for comparison. All the references above, without any exception, mention these two technologies at least, although they do not all mention others such as systems biology, or innovative healthcare, or innovative treatments. In this view, $p$-medicine would essentially consist in an agenda of molecularization and computerization of individual genomes. Indeed, neither the complex models of systems biology, nor big data biology, would have been possible without molecularization and computerization: they together constitute the infrastructure on which p-medicine could be built (on molecularization, see Chadarevian and Kamminga (2003); Boniolo and Nathan (2016); on computerization, see Stevens (2013)). However, it is still a long shot from molecularization and computerization of biology to personalized or stratified medicine.

In the list given above, the third technology to have played a role is not likely to be the change in the paradigm of care. Indeed, it has been advocated, with some reason, that molecularization changes our very concept of a person (Guchet 2016, pp. 22, 26, 32). Yet it surely is compatible with our traditional concepts of what a person is, nor does it challenge it more than the discovery of localized brain functions in the XIXth century.

The list of technologies given above suggests that innovative treatments may have played a significant role in the interpretation of these technologies as a unified program of p-medicine. Interestingly, let us imagine what more than a decade of talks of p-medicine would have sounded like, were there no innovative treatments to support them. Storing, comparing, characterizing genomes, exomes or transcriptomes is only a descriptive task: by no means does it make it medicine as there are no treatments, tailored or not. Molecularization and computerization provide advances in the understanding of how diseases work, but it could have been the case that it does not come with advances in treatments. However, less than a decade before the Human Genome Project, 'tailored' treatments had been developed under different categories, such as gene therapy and antibodies. As a matter of fact, only with personalized, precision or stratified effective treatments, could personalized, precision or stratified medicine be possible or, at least, convincing as a realistic agenda for medicine. A recent opinion article in The New England Journal of Medicine concluded that "[1] earning more about the variability of the molecular characteristics of individual tumors and its relationship to the natural history and outcome of disease is important research but has not facilitated choice of treatment" (Tannock and Hickman 2016). How could such fundamental research be properly called p-medicine? In the rest of the present paper, I suggest that the particular success of a new kind of treatments, monoclonal antibodies, has greatly helped the acceptance of molecular and computerized 
NEITHER FROM WORDS, NOR FROM VISIONS: UNDERSTANDING P-MEDICINE FROM INNOVATIVE TREATMENTS.

medicine as p-medicine.

\begin{tabular}{|l|l|}
\hline Drug repurposing & Chemical \\
\hline Muscle atrophy & Ursolic acid \\
\hline Lung cancer & $\begin{array}{l}\text { Cimetidine (a antiulcer } \\
\text { drug) }\end{array}$ \\
\hline $\begin{array}{l}\text { Hepatocellular carcinoma } \\
\text { (HCC) }\end{array}$ & $\begin{array}{l}\text { Chlorpromazine and trifluo- } \\
\text { perazine }\end{array}$ \\
\hline Hair growth & $\begin{array}{l}\text { Fluphenazine (an antipsy- } \\
\text { chotic drug) }\end{array}$ \\
\hline Osteoarthritic pain & $\begin{array}{l}\text { Phenoxybenzamine (an } \\
\text { anti-hypertensive drug) }\end{array}$ \\
\hline Inflammatory bowel disease & $\begin{array}{l}\text { Topiramate (an anticonvul- } \\
\text { sant drug) }\end{array}$ \\
\hline $\begin{array}{l}\text { Breast cancer (tamoxifen- } \\
\text { resistant) }\end{array}$ & $\begin{array}{l}\text { Phenothiazines (antipsy- } \\
\text { chotic and antihistaminic } \\
\text { drugs) }\end{array}$ \\
\hline Lung cancer & $\begin{array}{l}\text { Polyphyllin D (a potent } \\
\text { cytotoxic saponin) }\end{array}$ \\
\hline Gastric cancer & $\begin{array}{l}\text { Vorinostat (for cutaneous T } \\
\text { cell lymphoma) }\end{array}$ \\
\hline CNS injury & $\begin{array}{l}\text { Piperazine (antipsychotic } \\
\text { drug) }\end{array}$ \\
\hline
\end{tabular}

Table 2. Applications of the connectivity map project to drug repurposing in 2012 (after Qu and Rajpal 2012)

\begin{tabular}{|c|c|c|}
\hline & mab & TKI \\
\hline Number of studies/open studies ${ }^{1}$ & $3562 / 1026$ & $535 / 183$ \\
\hline $\begin{array}{l}\text { Number of phase } 1 \text { studies/open } \\
\text { phase } 1 \text { studies }{ }^{2}\end{array}$ & $1329 / 427$ & $177 / 69$ \\
\hline $\begin{array}{l}\text { Number of phase } 2 \text { studies/open } \\
\text { phase } 2 \text { studies }{ }^{2}\end{array}$ & $1845 / 507$ & $303 / 107$ \\
\hline $\begin{array}{l}\text { Number of phase } 3 \text { studies/open } \\
\text { phase } 3 \text { studies }{ }^{2}\end{array}$ & $583 / 155$ & $63 / 22$ \\
\hline $\begin{array}{l}\text { Number of phase } 4 \text { studies/open } \\
\text { phase } 4 \text { studies }{ }^{2}\end{array}$ & $111 / 40$ & $9 / 3$ \\
\hline Number of conditions ${ }^{2}$ & 848 & 307 \\
\hline Number of rare diseases ${ }^{2}$ & 232 & 84 \\
\hline $\begin{array}{l}\text { Number of sponsors/collabora- } \\
\text { tors (industry) }{ }^{2}\end{array}$ & 138 & 62 \\
\hline $\begin{array}{l}\text { Number of molecules with FDA } \\
\text { approval }^{3}\end{array}$ & 66 & 39 \\
\hline $\begin{array}{l}\text { Number of molecules under dev } \\
\text { lopment }\end{array}$ & & \\
\hline
\end{tabular}

Table 4. Relative importance of Monoclonal Antibodies (mabs) and tyrosine kinase inhibitors (TKI) in clinical studies.

\begin{tabular}{|c|c|c|}
\hline $\begin{array}{l}\text { Therapeutic } \\
\text { area }\end{array}$ & Drug & Biomarker \\
\hline \multirow{23}{*}{ Oncology } & Arsenic Trioxide & \multirow{2}{*}{ PML/RARa } \\
\hline & Tretinoin & \\
\hline & $\begin{array}{l}\text { Brentuximab } \\
\text { Vedotin }\end{array}$ & CD3o \\
\hline & Capecitabine & \multirow{2}{*}{ DPD } \\
\hline & Fluorouracil & \\
\hline & Cetuximab & \multirow[t]{2}{*}{$\overline{\text { EGFR }}$} \\
\hline & Panitumumab & \\
\hline & Crizotinib & ALK \\
\hline & $\begin{array}{l}\text { Denileukin Difi- } \\
\text { titox }\end{array}$ & CD25/IL2 \\
\hline & Exemestane & \multirow{3}{*}{ ER/PR } \\
\hline & Fulvestrant & \\
\hline & Letrozole & \\
\hline & Imatinib & $\begin{array}{l}\text { C-Kit, PDGFR, } \\
\text { FIP1L1 }\end{array}$ \\
\hline & Lapatinib & \multirow{4}{*}{ HER2 } \\
\hline & Pertuzumab & \\
\hline & Trastuzumab & \\
\hline & Everolimus & \\
\hline & Nilotinib & \multirow{3}{*}{$\mathrm{Ph}$ Chromsome } \\
\hline & Dasatinib & \\
\hline & Imatanib & \\
\hline & Rasburicase & G6PD \\
\hline & Tositumomab & CD2O antigen \\
\hline & Vemurafenib & BRAF \\
\hline \multirow{2}{*}{ Psychiatry } & Citalopram & CYP2C19 \\
\hline & Valproic acid & UCD \\
\hline \multirow{5}{*}{$\begin{array}{l}\text { Psychiatry, } \\
\text { Neurology }\end{array}$} & Pimozide & \multirow{5}{*}{ CYP2D6 } \\
\hline & Aripiprazole & \\
\hline & Iloperidone & \\
\hline & Trabenazine & \\
\hline & Thioridazine & \\
\hline Pulmonary & Ivacaftor & CFTR \\
\hline Analgesics & Celecoxib & CYP2C9 \\
\hline Antivirals & Maraviroc & $\mathrm{CCR}_{5}$ \\
\hline Hematology & Lenalidomide & $\begin{array}{l}\text { Chromosome 5q } \\
\text { deletion }\end{array}$ \\
\hline
\end{tabular}

Table 3. Drugs involving specific criteria for stratification or repurposing (after Food and Drug Administration 2014, pp. 37-8) 


\section{NEITHER FROM WORDS, NOR FROM VISIONS: UN- DERSTANDING P-MEDICINE FROM INNOVATIVE TREAT- MENTS.}

\section{4 - Monoclonal antibodies are the spearhead of $p$-medicine}

The only way for p-medicine to be convincing enough as a therapeutic project is to draw from successful treatments, specific enough to be contrasted to traditional treatments in terms of 'personalization' (or precision or ...), the possibility of a generalization to a sufficiently broad spectrum of diseases. First, it has to be successful treatment: just more accurate diagnosis or prognosis, would not properly be called a revolution in medicine in the end. Second, these treatments cannot simply be more efficient only since-comparable to traditional treatment-this would not fail to adequately justify a new label. Third, they cannot be limited in principle to a narrow range of pathological conditions, but must contain open possibilities. However efficient and personalized (or precise, or...) an innovative treatment for cancer might be, if it was in principle limited to cancer cells, it would not be called p-medicine, but p-oncology at best.

Although persuasive arguments may show more than one sort of innovative treatment has met these three conditions, clearly monoclonal antibodies do. First, some of them were dramatically more effective than standard treatments. Second, as antibodies target proteins, there is practically no limit to the potential effects of manipulated antibodies in an organism. Third, they have several specific features, such as: selective efficiency on stratified population; much less severe side effects in general; greater design; and less serendipity during development, which, in turn, lowers development cost. These are the features p-medicine is a generalization of. Now the rest of this section is dedicated to showing that monoclonal antibodies have a prominent position in contemporary treatments associated to p-medicine. The following section will focus on their specific features.

In general, 3 categories of innovative technologies have been involved in p-medicine: drug repurposing, stratification, and development of new drugs. Drug repurposing involves broadening the spectrum of action of a prescription drug to include a previously excluded population (see table 2 for examples and for a glimpse of the real scale of recent achievements by such practices). Stratification involves restricting the prescription of a drug to a fraction of a population that suffers from the same diagnosed condition. Both technologies may be needed simultaneously in some cases. A criterion is needed for both technologies: it is either a molecular, specific biomarker, or a more or less complex pattern of signs, the recognition of which involves big data processing, or both. Biomarkers and big data are the only innovations involved in drug repurposing and stratification. Yet the development of these innovative technologies is small compared to the development of new drugs, many of which also involve biomarkers, stratification and big data processing. If repurpos- ing and stratification obviously play a role in p-medicine, it is reasonable to focus on their use in the development of these new drugs. Indeed, as resorted to for traditional molecules, they remain marginal.

Table 3 shows 34 drugs with a biomarker that serves for "guidance". Note first that guidance is not "prescription". Citalopram, for instance, is a widely used antidepressant drug, generally prescribed without any biological test for the biomarker. Note also that if 5 treatments only were originally approved before 1998, many more are not properly "innovative". 14 of them are either tyrosine kinase inhibitors (TKI) or monoclonal antibodies, which makes it 15 innovative treatments, if one includes Ivacaftor as the FDA suggests.

To this list of innovative treatments, one should add fusion proteins (of which few are not mabs), cell therapy, gene therapy and immunotherapy (cytokines, lymphokines, imiquimod, and the targeted inhibition of PD-1 by mabs).

From a historical perspective, the first category of innovative drugs is TKI. Gleevec has been called a targeted drug as opposed to antimitotic drugs, long before the terms 'personalized' or 'precision' medicine were used in the current sense. It is not inappropriate, however, to call TKI a part of the p-medicine arsenal. Note that TKI ranksecond to mab in numerical importance in clinical research. The numbers of approved molecules are in a proportion of 3:2, but the number of studies, open studies for any phase, are in a proportion comprised between 5:1 and 10:1 (see table 4). An important part of the explanation is that the domain of application of TKI is almost entirely restricted to cancer therapy (with very few exceptions). On the other hand, mab can be used in almost all conditions. The FDA study established the proportions of "activities" involved in "personalized medicine" in 2012 as $33 \%$ in oncology, 21\% in cardiorenal medicine, $11 \%$ in neurology, $7 \%$ in both antiviral medicine and pulmonary medicine, $5 \%$ in psychiatry, and the remainder in other areas (Food and Drug Administration 2014, p. 55).

This brief overview of the field suggests that if one were to remove mabs, TKI, stem cell and immunotherapy would fail to justify wide acceptance of p-medicine outside of oncology. Only mabs are efficient, specific and ubiquitous enough for the concept of p-medicine to have emerged as a convincing description of successful technologies that may be generalized. However, this does not imply that only mabs qualify as instances of p-medicine. But it contends that they constitute the main, representative and archetypic, treatment of p-medicine. An investigation of their specific features could therefore be used as a benchmark for any general description of how p-medicine should be defined. 


\section{NEITHER FROM WORDS, NOR FROM VISIONS: UN- DERSTANDING P-MEDICINE FROM INNOVATIVE TREAT- MENTS.}

\section{5 - Mabs as archetypes for $p$ -medicine}

A comparison of mabs' main properties with p-medicine's offers some evidence of overlap, suggesting that the latter has indeed been inspired by the former. First, trastuzumab (Herceptin) is the most commonly cited example of p-medicine success. Second, all five practices described in section 2 are typically used in either the development, prescription or understanding of mabs. Trastuzumab is to be prescribed after testing for a biomarker, a cell receptor called 'HER/neu', which leads to stratification. Only up to a third of patients with breast cancer benefit from this treatment, most patients with breast cancer do not at all, and some patients with other forms and locations of cancer may also benefit from trastuzumab. Side effects are dramatically less severe and/or less likely to occur than with usual cancer treatments. Third, only mabs provide at the same time more personalization, stratification and precision in a credible bid to generalize the project to the whole of medical practice. Indeed, most of the development of biomarkers and of the practice of stratification, has actually come with mabs. Just to cite the example of multiple sclerosis, natalizumab is the most resorted to, but also alemtuzumab, rituximab, ocrelizumab, taclizumab are used in clinical practice. They also have much rarer side effects. Some of them are devoted for very specific uses, others, like natalizumab, are efficient in almost all individuals without significant side effects. Table 5 provides an idea of the development of biomarkers in the case of this condition.

The prominence of mabs in the field of p-medicine is not just an accidental fact. An explanation of the situation may indeed be found in molecular properties of mabs as opposed to other drugs. First of all, they are 'biologics', and mimic a natural class of proteins, antibodies, that have a significantly more specific binding behavior than traditional molecules. They also are metabolized in a different way that produces no active metabolites and makes them much less likely to elicit side effects. Most certainly they do have side effects, just as all treatments, but these are much more manageable and obviously less severe in many domains, especially in oncology, but also in neurology or rheumatology. mabs' important molecular mass explains both properties.

Moreover, they are produced with technologies of rational drug design rather than discovered serendipitously through screening. This is not unique to mabs, as it is also the case with TKI, even though the expression 'rational drug design' should not be taken too literally, which is emphasized by Keating and Cambrosio (2014). The difference lies in the much broader field of potential variations and applications of antibodies. Whereas targeted therapies as TKI focus on an enzyme that come to have a very specific activity in pathological processes as opposed to healthy mechanisms, mabs may in principle act upon every macromolecule in an organism.

\begin{tabular}{|l|c|c|c|}
\hline Established biomarkers & $\begin{array}{l}\text { Diagno- } \\
\text { sis }\end{array}$ & $\begin{array}{l}\text { Pro- } \\
\text { gnosis }\end{array}$ & $\begin{array}{l}\text { Treat- } \\
\text { ment } \\
\text { res- } \\
\text { ponse/ } \\
\text { side } \\
\text { effects }\end{array}$ \\
\hline $\begin{array}{l}\text { Cerebral spinal fluid-specific } \\
\text { oligoclonal bands }\end{array}$ & + & $(+)$ & - \\
\hline $\begin{array}{l}\text { Intrathecal immunoglobulin } \\
\text { production }\end{array}$ & + & $(+)$ & - \\
\hline $\begin{array}{l}\text { Intrathecal anti-viral immu- } \\
\text { noglobulin production }\end{array}$ & + & - & - \\
\hline Magnetic resonance imaging & + & $(+)$ & $(+)$ \\
\hline $\begin{array}{l}\text { Neutralizing antibodies } \\
\text { against beta-interferon }\end{array}$ & - & - & $(+)$ \\
\hline $\begin{array}{l}\text { Neutralizing antibodies } \\
\text { against natalizumab }\end{array}$ & - & - & + \\
\hline Antibodies against JC virus & - & - & + \\
\hline Aquaporin 4 antibodies & + & $(+)$ & $(+)$ \\
\hline Potential biomarkers & - & - & $(+)$ \\
\hline $\begin{array}{l}\text { CD56 bright natural killer } \\
\text { cells }\end{array}$ & - & - & $(+)$ \\
\hline Cytokines/chemokines & - & - & $(+)$ \\
\hline $\begin{array}{l}\text { Myelin oligodendrocyte } \\
\text { glycoprotein antibodies }\end{array}$ & $(+)$ & - & $(+)$ \\
\hline $\begin{array}{l}\text { Intrathecal/oligoclonal } \\
\text { immunoglobulin M produc- } \\
\text { tion }\end{array}$ & - & - & $(+)$ \\
\hline Transcriptomics & - & & $(+)$ \\
\hline Genetics & & + & $(+)$ \\
\hline
\end{tabular}

Table 5. Summary of established and potential biomarkers for diagnosis, prognosis, and treatment of multiple sclerosis (in Derfuss 2012). ' + ' means that it is used in clinical practice, ' $(+)$ ' that more clinical data is needed and '-' that there is no clear evidence.

The question is not whether a specific antibody exists, which acts on target such and such, but rather, how to design a monoclonal antibody which will. Let us imagine that the whole class of TKI and the whole class of mabs have been developed and tested. Given what we now know, nobody would expect the class of TKI to cure many other pathological conditions apart from cancers, whereas many would expect one antibody or another to potentially cure almost everything. In the end, the mode of action of mabs is sometimes not just compensatory, mimicking the action of a missing molecule - just as L-dopa or insulin -, or corrective, counterbalancing the action of another one - just as TKI, antibiotics or selective serotonin reuptake inhibitors. It may be transformative in the sense that it forces a mechanism to actually work in an entirely different way, one that is unnatural in a sense. Socalled superagonist mabs are an example: they bypass the 
REVUE

DE LA SOCIÉTÉ

DE PHILOSOPHIE

DES SCIENCES

\section{NEITHER FROM WORDS, NOR FROM VISIONS: UN- DERSTANDING P-MEDICINE FROM INNOVATIVE TREAT- MENTS.}

natural binding mechanism and some produce complex phenomena of cross-linking (as was the case, with catastrophic consequences, for TGN1412 see Lemoine's (2017). Whereas it is possible to predict whether, how strongly and how specifically mabs will bind to a given molecule drawing from traditional preclinical models, it would require sophisticated systems biology to predict the overall effect on human organisms.

All of this makes mabs, by nature, a deposit of potential magic bullets: that they actually always work well is, of course, a different question. There is no doubt that some are extremely efficient. Trastuzumab (Herceptin) is the best known, and many others are resorted to in a wide variety of pathological conditions. But as antibodies, they also carry a risk of immunogenicity that limits their efficiency in time. The major limit, however, is individual variability.

Indeed, this extreme specificity in binding logically involves that mabs are, in general, much more subjected to individual variability than other drugs. This is initially the reason why they much more often require companion tests and stratification techniques, as compared to other drugs. This is also in response to the challenges raised by the development of mabs, that biobanks and complex algorithms based on systems biology have been developed, especially in cancer research.

All this shows that mabs involve most changes associated with 'p-medicine'. None of these changes is uniquely theirs, some will possibly be developed further by other technologies legitimately associated with p-medicine. However, only mabs have so far involved all of them at the same time and thereby justify that these technologies may be associated in one project, whatever 'p-medicine' should be called. Moreover, mabs have so far constituted the major part of successful innovations in the last decade or two in medicine.

\section{6 - Conclusion: The name and the thing}

Science often incorporates new words from common language via analogy. 'Personalized' has been a buzzword since the early 200os: cars, operating systems on computers, stamps, novels, mugs, T-shirts, educational plans, health plans and assessments of the evolution of prices have all been personalized. There is no technical sense in which the word is stipulated either in medicine or elsewhere, nor probably any unique specific sense. This is the reason why anyone, in medicine, may apply the term to what they are currently doing and use it to emphasize any number of properties, from humane care to the use of molecular biomarkers, or whatever may, however remotely, share a property with anything else that can be called 'personalized'. Of course, any other word emphasizing one of these same properties, yet with different connotations, as 'precision', may replace the original term because it more exactly describes what one wants to emphasize. Then the same process may start again with this new term. A good example is the emergence of "precision psychiatry". This term has been used to describe an ongoing project, the "Research Domain Criteria" or RDoC project (Insel 2014). This project involves neither different treatments, nor bypassing established disease entities through stratification, but the establishment of which modules dysfunction in mental disorders, on the basis of which true disease entities, efficient treatments, etc., may be used. Whereas the molecularization of disease entities had been achieved before precision medicine emerged, precision psychiatry is in part an agenda of molecularization of mental disorders. The analogy is thus quite strained.

However, it is convenient for philosophers to suppose that there exists a clear sense in which the term is used, or even a prominent sense, or that there are real distinctions between 'precision', 'personalized', 'P4', which it would be the job of philosophers par excellence to disentangle. It does not mean that all philosophers endorse this view (for a stark counterexample see De Grandis and Halgunset's [2016]), but it makes the traditional use of conceptual analysis easier, or even possible. The distinctions are there in the world, waiting for philosophers to make them clear and explicit. Often, claims about what personalized medicine 'is' conflict with what someone else thinks it really is (or should be). Obviously, such objections presupposed a meaning of personalization, based on whatever project or agenda the term may refer to, instead of considering the properties of this and other current treatments actually characterized as examples of 'personalized' medicine. The current paper attempts to shift attention from the meaning and connotations of words to treatments actually introduced in clinical practice or under development.

Whatever p-medicine really is, we can agree that it is not classical medicine, vaguely defined as a set of more or less outdated technologies. This hardly would define what it is, even negatively, yet one is sometimes left with the impression - not in philosophical, but in scientific articles - that it is the only argument made. What it is not really, however, is one articulated agenda, the formulation of which could be found in editorials or even in a couple of programmatic papers (a point made by De Grandis and Halgunset [2016]). Such agendas are too anticipative to be assessable, too broad to be efficient, too many to be describable. What it really is, is, at its core, the actual, current development of a new class of treatments, monoclonal antibodies, characterized with many of the properties usually attributed to p-medicine: molecular approach, biomarkers, stratification, big data, systems biology, questioning received disease entities, few side effects, some dramatic successes, a lot of investment, hundreds of candidate molecules, and an unlimited field of potential 
REVUE

DE LA SOCIÉTÉ

DE PHILOSOPHIE DES SCIENCES

\section{NEITHER FROM WORDS, NOR FROM VISIONS: UN- DERSTANDING P-MEDICINE FROM INNOVATIVE TREAT- MENTS.}

applications. By 'really is', I mean what has been achieved, not what we should consider it is 'by nature.' This is not an 'essence' of p-medicine, i.e. something that is by definition 'precise' or 'personalized', etc., but a fact that could have been interpreted and named otherwise. Around the core, the mantel is composed of less successful, or more localized, or more potential, technologies characterized by one, or some of these features, such as: clouds of data points about patients' health without enough computer power or statistical power yet, much more specific drugs with a limited range of applications, genomic sequencing producing a surfeit of unused information. All this construction would have collapsed if it had not been for monoclonal antibodies. P-medicine is a multifaceted conceptual generalization of the many reasons why some monoclonal antibodies have been successful.

\section{Acknowledgements}

Brendan Clarke, Marie Darrason, Elodie Giroux, Kathryn Tabb, Hervé Watier and two anonymous reviewers for precious comments.

\section{RÉFÉRENCES}

ABRAHAMS, Edward, GINSBURG, Geoffrey S., SILVER, Mike. 2005. The Personalized Medicine Coalition: Goals and Strategies. American Journal of Pharmacogenomics: Genomics-Related Research in Drug Development and Clinical Practice, 5 (6), 345-55. Article

ADZHUBEI, Ivan A., SCHMIDT, Steffen, PESHKIN, Leonid, RAMENSKY, Vasily E., GERASIMOVA, Anna, BORK, Peer, KONDRASHOV, Alexey S., SUNYAEV, Shamil R.. 2010. A Method and Server for Predicting Damaging Missense Mutations. Nature Methods, 7 (4), 248-49. Article

BARABÁSI, Albert-László, GULBAHCE, Natali, LOSCALZO, Joseph. 2011. Network medicine: a network-based approach to human disease. Nature reviews. Genetics, 12 (1), 56-68. Article

BARH Margaret, BLUM Debmalya and MADIGAN Kenneth. 2011. OMICS: Biomedical Perspectives and Applications. Boca Raton, London, New York : CRC Press. Book

Biomarkers Definitions Working Group. 2001. Biomarkers and Surrogate Endpoints: Preferred Definitions and Conceptual Framework. Clinical Pharmacology and Therapeutics, 69 (3), 89-95. Article

BOENINK, Marianne. 2010. Molecular Medicine and Concepts of Disease: The Ethical Value of a Conceptual Analysis of Emerging Biomedical Technologies. Medicine, Health Care and Philosophy, $13(1), 11-23$.

BONIOLO, Giovanni, NATHAN, Marco J. 2016. Philosophy of Molecular Medicine: Foundational Issues in Research and Practice. London \& New York : Routledge. Book

BRAGAZZI, Nicola L. 2013. Rethinking Psychiatry with OMICS Science in the Age of Personalized $\mathrm{P}_{5}$ Medicine: Ready for Psychiatome? Philosophy, Ethics, and Humanities in Medicine, 8 (1), 4. Article
CANUEL, Vincent, RANCE, Bastien, AVILLACH, Paul, DEGOULET, Patrice, BURGUN, Anita. 2015. Translational Research Platforms Integrating Clinical and Omics Data: A Review of Publicly Available Solutions. Briefings in Bioinformatics, 16 (2), 280-90. Article

CHADAREVIAN, Soraya de, KAMMINGA, Harmke. 2003. Molecularizing Biology and Medicine: New Practices and Alliances, 1920s to 1970s. 1reéd. London \& New York: Taylor \& Francis. Book CHAN, Isaac S., GINSBURG, Geoffrey S. 2011. Personalized Medicine: Progress and Promise. Annual Review of Genomics and Human Genetics, 12, 217-44. Article

DE GRANDIS, Giovanni, HALGUNSET, Vidar. 2016. Conceptual and terminological confusion around personalised medicine: a coping strategy. BMC Medical Ethics, 17, 43. Article

DERFUSS, Tobias. 2012. Personalized Medicine in Multiple Sclerosis: Hope or Reality? BMC Medicine, 10, 116. Article

FAN, Jianqing, HAN, Fang, HAN, Liu. 2014. Challenges of Big Data analysis. National Science Review, 1 (2), 293-314. Article

FISCHER, Tobias, LANGANKE, Martin, MARSCHALL, Paul, MICHL, Susanne. 2015. Individualized Medicine: Ethical, Economical and Historical Perspectives. Dordrecht : Springer. Book FLECK, Leonard M. 2010. Personalized Medicine's Ragged Edge . Hastings Center Report, 40 (5), 16-18. Article Food and Drug Administration. 2014. Paving the Way for Personalized Medicine: FDA's Role in a New Era of Medical Product Development. CreateSpace Independent Publishing Platform. Web GAMULIN, Stjepan. 2016. The Forthcoming Era of Precision Medicine. Acta Medica Academica, 45 (2), 152-57. Article

GREEN, Sara, and VOGT, Henrik. 2016. Personalizing Medicine: Disease Prevention in silico and in socio. Humana.Mente Journal of Philosophical Studies, 30, 105-35. Article

GUCHET, Xavier. 2016. La Médecine personnalisée: Un essai philosophique. 1re éd. Paris : Les Belles Lettres.

HEDGECOE, Adam. 2004. The Politics of Personalised Medicine: Pharmacogenetics in the Clinic. New York : Cambridge University Press. Book

HOOD, Leroy. 2013. Systems Biology and p4 Medicine: Past, Present, and Future. Rambam Maimonides Medical Journal, 4 (2), eoo12. Article

HOOD, Leroy, and FLORES, Mauricio. 2012. A Personal View on Systems Medicine and the Emergence of Proactive 44 Medicine: Predictive, Preventive, Personalized and Participatory. New Biotechnology, 29 (6), 613-24. Article

HOOD, Leroy, and FRIEND, Stephen H. 2011. Predictive, Personalized, Preventive, Participatory ( $\mathrm{P} 4)$ Cancer Medicine. Nature Reviews Clinical Oncology, 8 (3), 184-87. Article

IDEKER, Trey, GALITSKI, Timothy, HOOD Leroy. 2001. A New Approach to Decoding Life: Systems Biology. Annual Review of Genomics and Human Genetics, 2, 343-72. Article

INSEL, Thomas R. 2014. The NIMH Research Domain Criteria (RDoC) Project: Precision Medicine for Psychiatry. The American Journal of Psychiatry, 171 (4), 395-97. Article JUENGST, Eric, MCGOWAN, Michelle L., FISHMAN, Jennifer R., SETTERSTEN, Richard A. 2016. From "Personalized" to "Precision" Medicine: The Ethical and Social Implications of Rhetorical 
REVUE

DE LA SOCIÉTÉ

DE PHILOSOPHIE

DES SCIENCES

\section{NEITHER FROM WORDS, NOR FROM VISIONS: UN- DERSTANDING P-MEDICINE FROM INNOVATIVE TREAT- MENTS.}

POKORSKA-BOCCI, Anna, STEWART, Alison, SAGOO, Gurdeep S., HALL, Alison, KROESE, Mark, BURTON, Hilary. 2014. "Personalized medicine": what's in a name? Personalized Medicine, 11 (2), 197-210. Article

PRAVETTONI, Gabriella, GORINI, Alessandra. 2011. A P5 Cancer Medicine Approach: Why Personalized Medicine Cannot Ignore Psychology. Journal of Evaluation in Clinical Practice, 17 (4), 594-96. Article

QU, Xiaoyan A., RAJPAL, Deepak K. 2012. Applications of Connectivity Map in Drug Discovery and Development. Drug Discovery Today, 17 (23-24), 1289-98. Article

SCHLEIDGEN, Sebastian, KLINGLER, Corinna, BERTRAM, Teresa, ROGOWSKI, Wolf H., MARCKMANN, Georg. 2013. What is personalized medicine: sharpening a vague term based on a systematic literature review. BMC Medical Ethics, 14, 55. Article SOON, Wendy Weijia, HARIHARAN, Manoj, SNYDER, Michael P. 2013. High-throughput Sequencing for Biology and Medicine. Molecular Systems Biology, 9 (1), 640. Article

STEVENS, Hallam. 2013. Life Out of Sequence: A Data-driven History of Bioinformatics. Chicago : University of Chicago Press. Book

STRIMBU, Kyle, TAVEL, Jorge A. 2010. What are Biomarkers? Current opinion in HIV and AIDS, 5 (6), 463-66. Article

TANNOCK, Ian F., HICKMAN, John A. 2016. Limits to Personalized Cancer Medicine. New England Journal of Medicine, 375 (13), 1289-94. Article

TRUSHEIM, Mark R., BERNDT, Ernst R., DOUGLAS, Frank L. 2007. Stratified Medicine: Strategic and Economic Implications of Combining Drugs and Clinical Biomarkers. Nature Reviews. Drug Discovery, 6 (4), 287-93. Article

TUTTON, Richard. 2012. Personalizing Medicine: Futures Present and Past. Social Science \& Medicine (1982), 75 (10), 1721-28. Article

WORTHEY, Elizabeth A., MAYER, Alan N., SYVERSON, Grant D., HELBLING, Daniel, BONACCI, Benedetta B., DECKER, Brennan, SERPE, Jaime M. et al. 2011. Making a Definitive Diagnosis: Successful Clinical Application of Whole Exome Sequencing in a Child with Intractable Inflammatory Bowel Disease. Genetics in Medicine: Official Journal of the American College of Medical Genetics, 13 (3), 255-62. Article

\section{CONTACT ET COORDONNÉES}

\section{Maël Lemoine}

Université de Tours

Faculté de médecine

Département de SHS

10 Bd Tonnellé

37000 Tours

lemoine@univ-tours.fr 